\title{
Prevalence and associated factors of hand and oral hygiene behaviour among adolescents in Dominican Republic, Suriname and Trinidad and Tobago
}

Supa Pengpid ${ }^{1,2}$ and Karl Peltzer ${ }^{3}$

${ }^{1}$ ASEAN Institute for Health Development, Mahidol University, Salaya, Phutthamonthon, Nakhon Pathom, Thailand; email: supaprom@yahoo.com

${ }^{2}$ Department of Research Administration and Development, University of Limpopo, Turfloop, South Africa

${ }^{3}$ Department of Psychology, University of the Free State, Bloemfontein, South Africa

Corresponding author at: Karl Peltzer, University of the Free State, Bloemfontein, South Africa; Email: kfpeltzer@gmail.com

\begin{abstract}
The study aimed to estimate the prevalence and correlates of oral hygiene $(\mathrm{OH})$ and hand hygiene (HH) behaviour among school adolescents in three Caribbean countries. In all, 7,476 school adolescents (median age 14 years), from Dominican Republic, Suriname and Trinidad and Tobago responded the cross-sectional "Global School-based Student Health Survey” (GSHS) in 2016-2017. The prevalence poor $\mathrm{OH}$ (tooth brushing $<2$ times/day) was $16.9 \%$, poor $\mathrm{HH}$ (not always before meals) was $68.2 \%$, poor $\mathrm{HH}$ (not always after toilet) was $28.4 \%$ and poor $\mathrm{HH}$ (not always with soap) was $52.7 \%$. In adjusted logistic regression analysis, current cannabis use, inadequate fruit and vegetable intake, poor mental health and low parental support increased the odds for poor $\mathrm{OH}$. Rarely or sometimes experiencing hunger, trouble from alcohol use, inadequate fruit and vegetable intake, poor mental health, and low parental support were associated with poor HH (before meals, and/or after toilet, and/or with soap). The survey showed poor $\mathrm{OH}$ and $\mathrm{HH}$ behaviour practices. Several sociodemographic factors, health risk behaviours, poor mental health and low parental
\end{abstract}


support were found associated with poor $\mathrm{OH}$ and/or $\mathrm{HH}$ behaviour that can assist with tailoring $\mathrm{OH}$ and $\mathrm{HH}$ health promotion.

Key words: Personal hygiene, school adolescents, correlates, Caribbean

\section{Introduction}

Oral hygiene $(\mathrm{OH})$ ("tooth brushing $\geq 2$ /day") is a major tool to prevent and control periodontal diseases and dental caries [1]. Good hand hygiene (HH) using soap can "avert 0.5-1.4 million deaths every year" [2]. Despite the potential positive impact of good $\mathrm{OH}$ and $\mathrm{HH}$, the prevalence of good $\mathrm{OH}$ and $\mathrm{HH}$ practices among adolescents is low [3]. There is a lack of recent national information on $\mathrm{OH}$ and $\mathrm{HH}$ among adolescents in Caribbean countries, such as Dominican Republic, Suriname and Trinidad and Tobago [4]. Among school adolescent in 15 Latin American and Caribbean countries from 2006-2011, 2\%-9\% reported infrequent (<one time/day) tooth brushing and 2\%-7\% infrequent (never or rarely) $\mathrm{HH}$ after toilet use [4]. In the Dominican Republic, "risk factors for diarrhea and cholera transmission include poor adherence to water, sanitation, and hygiene (WASH) practices such as consistent hand washing" [5-7]. In Suriname, the prevalence of caries of schoolchildren was moderate to high (using WHO criteria), and majority of children had dental caries [8]. The prevalence of teeth cleaning ( $\geq 2$ day) among adults in the Dominican Republic was 94.2\% [9].

In a multicountry investigation among school adolescents most (80\%) reported daily tooth brushing, and more than one in 20 students brushed their teeth "less than once a day or never" in half of the countries [10], including $10.0 \%$ in Zambia [11]. In a study among school-going adolescents in nine African countries, 22.7\% had poor $\mathrm{OH}$ (tooth brushing <2/day), 62.2\% had poor $\mathrm{HH}$ (not always before meals), $58.4 \%$ poor $\mathrm{HH}$ (not always after toilet), and $35.0 \%$ poor $\mathrm{HH}$ (not always with soap) [12], while in six Southeast Asian countries, 17.1\% had poor $\mathrm{OH}, 44.8 \%$ had poor $\mathrm{HH}$ (before meals), 31.9\% poor HH (after toilet), and 55.8\% poor HH (with soap) [3].

As reviewed earlier [3], "factors associated with poor $\mathrm{OH}$ among adolescents include sociodemographic variables (early adolescence, male sex, and lower wealth status), health risk behaviours, such as insufficient fruit and vegetable consumption, physical inactivity, and tobacco use, poor mental health and lack of parental support." Factors associated with poor HH among adolescents [3], include, "male sex, lower wealth status, health risk behaviours, such as low fruit and 
vegetable consumption, sedentary behaviour and physical inactivity, and substance use, poor mental health, and lack of parental support."

Recent national data on the prevalence and correlates of $\mathrm{OH}$ and $\mathrm{HH}$ among adolescents are lacking in the Caribbean region. Therefore, the aim of this study assess the prevalence and associated factors of poor $\mathrm{OH}$ and $\mathrm{HH}$ among adolescents in the Dominican Republic, Suriname and Trinidad and Tobago in 2016-2017.

\section{Methods}

\section{Sample and procedure}

Cross-sectional nationally representative survey data from the 2016 Dominican Republic, 2016 Suriname, and 2017 Trinidad and Tobago GSHS were analyzed [13]. The sampling approach included a two stage sampling design, including schools and classes. All school students present in a selected classroom were eligible to participate by filling in a self-administered anonymous questionnaire [13]. Information that is more detailed can be publically accessed [13]; the overall response rate was $63 \%$ in the Dominican Republic, $83 \%$ in Suriname, and $89 \%$ in Trinidad and Tobago [13].

\section{Measures}

The GSHS questions used [13] are described in supplementary file 1.

Oral hygiene was sourced from the question "During the past 30 days, how many times per day did you usually clean or brush your teeth?" "1=I did not clean or brush my teeth during the past 30 days $6=4$ or more times per day (coded $1-3=1$ and $4-6=0$ )"

Hand hygiene was sourced from three items. "During the past 30 days, how often did you wash your hands before eating/after using the toilet or latrine/use soap?” Response options ranged from " $1=$ never to $5=$ always (coded 1-4=1 and 5=0)" "The poor mental health was defined as $0=0$ low, $1=1$ medium and 2-5=2 high based on the positive responses to the items no close friends, loneliness, anxiety, suicidal ideation and suicide attempt. The four items on parental or guardian support were summed, and classified into three groups, 0-1 low, 2 medium and 3-4 high support." $[3]$. 


\section{Data analysis}

Statistical analyses were conducted with "STATA software version 15 (Stata Corporation, College Station, Texas, USA)", taking into account the sampling weights and multi-stage sampling design. Multivariable logistic regression analyses were used to predict the covariates of poor OH (tooth brushing <2/day), poor $\mathrm{HH}$ (not always before meals), poor $\mathrm{HH}$ (not always after toilet), and poor HH (not always with soap). Missing variable information was excluded from the analysis and pvalues $<0.05$ indicated statistical significance.

\section{Results}

\section{Sample characteristics and hygiene behaviour}

The study sample comprised 7,476 school adolescents (14 years median age; IQR=13-16) from the Dominican Republic, Suriname and Trinidad and Tobago. In all three countries, the prevalence poor $\mathrm{OH}$ (<twice a day tooth brushing) was $16.9 \%$, poor $\mathrm{HH}$ (not always before meals) was $68.2 \%$, poor $\mathrm{HH}$ (not always after toilet) $28.4 \%$ and poor $\mathrm{HH}$ (not always with soap) was $52.7 \%$ (see Table 1 ).

Table 1: Characteristics of the sample and hygiene behaviour in Dominican Republic, Suriname, and Trinidad and Tobago, 2016-2017

\begin{tabular}{|l|l|l|l|l|l|}
\hline Variable & Sample & \multicolumn{3}{l|}{ Not always hand hygiene } & $\begin{array}{l}\text { Oral } \\
\text { hygiene }\end{array}$ \\
\hline & & $\begin{array}{l}\text { Before } \\
\text { meals }\end{array}$ & $\begin{array}{l}\text { After } \\
\text { toilet }\end{array}$ & With soap & $\begin{array}{l}\text { Tooth } \\
\text { brushing } \\
<2 / \text { day }\end{array}$ \\
\hline & & & & & \\
\hline All & N (\%) & $\%$ & $\%$ & $\%$ & $\%$ \\
\hline Sociodemographic variables & 7476 & 68.2 & 28.4 & 52.7 & 16.9 \\
\hline Country & & & & & \\
\hline Dominican Republic & & & & & \\
\hline Suriname & $1481(19.8)$ & 69.9 & 30.7 & 51.2 & 16.2 \\
\hline Trinidad and Tobago & $2126(28.4)$ & 46.0 & 14.1 & 56.2 & 14.3 \\
\hline Gender & $3869(51.8)$ & 66.6 & 19.8 & 60.3 & 22.1 \\
\hline Female & & & & & \\
\hline Male & $3916(50.6)$ & 68.1 & 28.0 & 52.2 & 14.0 \\
\hline Age in years & $3466(49.4)$ & 67.5 & 26.3 & 51.7 & 16.8 \\
\hline$\leq 13$ & & & & & \\
\hline $14-15$ & $2210(29.7)$ & 56.9 & 22.8 & 50.1 & 17.0 \\
\hline$\geq 16$ & $3148(42.3)$ & 67.5 & 26.1 & 47.4 & 14.9 \\
\hline $\begin{array}{l}\text { Went hungry } \\
\text { Never }\end{array}$ & $2083(28.0)$ & 71.8 & 31.4 & 57.3 & 17.8 \\
\hline
\end{tabular}




\begin{tabular}{|l|l|l|l|l|l|}
\hline $\begin{array}{l}\text { Rarely/sometimes } \\
\text { Mostly/always }\end{array}$ & $\begin{array}{l}2802(33.9) \\
589(3.9)\end{array}$ & $\begin{array}{l}75.2 \\
67.2\end{array}$ & 35.9 & 60.0 & 17.9 \\
\hline Health risk behaviour & & & & 53.5 & 26.0 \\
\hline Current tobacco use & $910(12.1)$ & 73.9 & 44.3 & 59.4 & 31.2 \\
\hline Trouble from alcohol use & $661(12.1)$ & 71.8 & 41.5 & 69.0 & 25.1 \\
\hline Current cannabis use & $365(4.4)$ & 67.5 & 42.6 & 62.1 & 32.1 \\
\hline Fruit/Vegetables $(<5$ servings/day) & $5756(82.4)$ & 70.5 & 28.2 & 54.5 & 17.6 \\
\hline Sedentary behaviour & $3354(47.4)$ & 71.3 & 27.8 & 55.4 & 18.5 \\
\hline Physical inactivity & $5920(86.6)$ & 68.3 & 28.5 & 53.1 & 17.5 \\
\hline No physical education & $2117(27.3)$ & 72.7 & 33.4 & 58.2 & 21.5 \\
\hline Poor mental health & & & & & \\
$\quad$ Low & $4200(64.4)$ & 64.7 & 23.1 & 50.3 & 12.9 \\
$\quad$ Moderate & $1440(18.4)$ & 71.1 & 32.1 & 55.0 & 20.2 \\
High & $1309(17.3)$ & 74.1 & 37.3 & 55.8 & 19.7 \\
\hline Protective factors & & & & & \\
\hline School attendance & $5658(74.9)$ & 67.6 & 25.9 & 50.9 & 15.4 \\
\hline Peer support & & & & & \\
$\quad$ Low & $2305(32.3)$ & 67.8 & 34.7 & 55.7 & 20.6 \\
$\quad$ Moderate & $2067(29.0)$ & 74.8 & 35.8 & 61.9 & 21.9 \\
High & $2756(38.7)$ & 64.9 & 20.0 & 47.2 & 11.5 \\
\hline Parental support & & & & & \\
$\quad$ Low & $1811(35.5)$ & 78.8 & 37.1 & 64.1 & 22.2 \\
Medium & $2179(27.2)$ & 68.0 & 28.7 & 56.7 & 18.1 \\
High & $6782(37.3)$ & 58.3 & 16.7 & 40.6 & 9.2 \\
\hline Parents not using tobacco & $5506(85.3)$ & 67.8 & 27.5 & 51.5 & 15.3 \\
\hline
\end{tabular}

\section{Associations with poor oral and hand hygiene}

In adjusted logistic regression analysis, being students from Trinidad and Tobago (adjusted odds ratio-AOR: 1.63, 95\% Confidence Interval-CI: 1.23-2.14), current cannabis use (AOR: 2.41, 95\% CI: 1.31-4.45), inadequate fruit and vegetable intake (AOR: 2.24, 95\% CI: 1.02-4.93), and high poor mental health (AOR: 1.39, 95\% CI: 1.00-1.91) increased the odds and high parental support (AOR: 0.70, 95\% CI: 0.51-0.97) decreased the odds for poor oral hygiene.

Compared to students from Dominican Republic, students from Suriname and Trinidad and Tobago had lower odds for poor HH before meals and after toilet, but higher odds for with soap. Male sex had lower odds for poor $\mathrm{HH}$ after toilet, and older adolescents had higher odds for poor HH with soap. Rarely or sometimes experiencing hunger was positively and high parental support was negatively associated with all three poor HH indicators (before meals, after toilet and with soap). Inadequate fruit and vegetable intake and moderate peer support were associated with poor $\mathrm{HH}$ after meals and with soap, while moderate or high poor mental health increased the odds for poor $\mathrm{HH}$ after meals and after toilet. Trouble from alcohol use was positively associated with poor 
$\mathrm{HH}$ with soap, and physical inactivity and sedentary behaviour were negatively associated with poor $\mathrm{HH}$ after toilet (see Table 2).

Table 2: Associations with poor oral hygiene $(\mathrm{OH})$ and poor hand hygiene $(\mathrm{HH})$ indicators

\begin{tabular}{|c|c|c|c|c|}
\hline Variable & Poor OH & $\begin{array}{l}\text { Poor HH (before } \\
\text { meals) }\end{array}$ & $\begin{array}{l}\text { Poor HH (after } \\
\text { toilet) }\end{array}$ & Poor HH (with soap) \\
\hline & AOR (CI 95\%) & AOR (CI 95\%) & AOR (CI 95\%) & AOR (CI 95\%) \\
\hline \multicolumn{5}{|c|}{ Sociodemographic variables } \\
\hline \multicolumn{5}{|l|}{ Country } \\
\hline Dominican Republic & 1 (Reference) & 1 (Reference) & 1 (Reference) & 1 (Reference) \\
\hline Suriname & $1.09(0.72,1.64)$ & $0.31(0.25,0.37)^{* * *}$ & $0.29(0.20,0.42)^{* * *}$ & $1.34(1.13,1.59)^{* * *}$ \\
\hline Trinidad and Tobago & $1.63(1.23,2.14)^{* * *}$ & $0.77(0.61,0.97)^{*}$ & $0.41(0.31,0.55)^{* * *}$ & $1.43(1.13,1.82)^{* *}$ \\
\hline \multicolumn{5}{|l|}{ Gender } \\
\hline Female & 1 (Reference) & 1 (Reference) & 1 (Reference) & 1 (Reference) \\
\hline Male & $0.95(0.66,1.37)$ & $0.81(0.54,1.21)$ & $0.76(0.58,0.98)^{*}$ & $0.83(0.63,1.09)$ \\
\hline \multicolumn{5}{|l|}{ Age in years } \\
\hline$\leq 13$ & 1 (Reference) & 1 (Reference) & 1 (Reference) & 1 (Reference) \\
\hline $14-15$ & $1.10(0.69,1.73)$ & $1.38(0.98,1.93)$ & $1.07(0.78,1.47)$ & $0.96(0.69,1.34)$ \\
\hline$\geq 16$ & $0.95(0.71,1.26)$ & $1.57(1.00,2.47)$ & $1.21(0.75,1.97)$ & $1.57(1.04,2.38)^{*}$ \\
\hline $\begin{array}{l}\text { Went hungry } \\
\text { Never } \\
\text { Rarely/sometimes } \\
\text { Mostly/always }\end{array}$ & $\begin{array}{l}1 \text { (Reference) } \\
1.11(0.80,1.52) \\
1.72(0.85,3.49)\end{array}$ & $\begin{array}{l}1 \text { (Reference) } \\
1.51(1.25,1.84)^{* * *} \\
0.94(0.57,1.54)\end{array}$ & $\begin{array}{l}1 \text { (Reference) } \\
2.04(1.67,2.49)^{* * *} \\
1.75(0.73,4.19)\end{array}$ & $\begin{array}{l}1 \text { (Reference) } \\
1.40(1.02,1.93)^{*} \\
1.35(0.76,2.41)\end{array}$ \\
\hline \multicolumn{5}{|l|}{ Health risk behaviour } \\
\hline Current tobacco use & $0.83(0.56,1.23)$ & $0.89(0.52,1.55)$ & $0.81(0.95,2.49)$ & $0.73(0.46,1.16)$ \\
\hline Trouble from alcohol use & $1.09(0.55,2.19)$ & $1.03(0.61,1.75)$ & $1.31,0.78,2.20)$ & $2.05(1.17,3.25)^{*}$ \\
\hline Current cannabis use & $2.41(1.31,4.45)^{* *}$ & $0.60(0.24,1.52)$ & $1.05(0.24,4.57)$ & $1.25(0.42,3.69)$ \\
\hline $\begin{array}{l}\text { Fruit/Vegetables }(<5 \\
\text { servings/day) }\end{array}$ & $2.24(1.02,4.93)^{*}$ & $1.69(1.27,2.25)^{* * *}$ & $1.18(0.83,1.67)$ & $1.53(1.01,2.32)^{*}$ \\
\hline Sedentary behaviour & $0.89(0.62,1.28)$ & $1.07(0.87,1.32)$ & $0.62(0.42,0.91)^{*}$ & $1.03(0.85,1.26)$ \\
\hline Physical inactivity & $1.12(0.86,1.48)$ & $0.73(0.49,1.10)$ & $0.65(0.51,0.82)^{* * *}$ & $0.81(0.52,1.27)$ \\
\hline No physical education & $1.11(0.77,1.62)$ & $1.10(0.72,1.68)$ & $0.98(0.66,1.47)$ & $1.02(0.64,1.61)$ \\
\hline $\begin{array}{l}\text { Poor mental health } \\
\text { Low } \\
\text { Moderate } \\
\text { High }\end{array}$ & $\begin{array}{l}1 \text { (Reference) } \\
1.22(0.82,1.83) \\
1.39(1.00,1.91)^{*}\end{array}$ & $\begin{array}{l}1 \text { (Reference) } \\
1.38(1.03,1.86)^{*} \\
1.37(0.95,1.97)\end{array}$ & $\begin{array}{l}1 \text { (Reference) } \\
1.51(0.89,2.57) \\
1.69(1.30,2.18)^{* * *}\end{array}$ & $\begin{array}{l}1 \text { (Reference) } \\
1.00(0.73,1.36) \\
0.87(0.59,1.29)\end{array}$ \\
\hline \multicolumn{5}{|l|}{ Protective factors } \\
\hline School attendance & $0.84(0.47,1.50)$ & $1.10(0.85,1.43)$ & $0.81(0.61,1.07)$ & $0.89(0.76,1.05)$ \\
\hline $\begin{array}{l}\text { Peer support } \\
\text { Low } \\
\text { Moderate } \\
\text { High }\end{array}$ & $\begin{array}{l}1 \text { (Reference) } \\
0.97(0.72,1.32) \\
0.79(0.42,1.49)\end{array}$ & $\begin{array}{l}1 \text { (Reference) } \\
1.73(1.27,2.34)^{* * *} \\
1.39(0.90,2.13)\end{array}$ & $\begin{array}{l}1 \text { (Reference) } \\
1.13(0.69,1.85) \\
0.87(0.55,1.38)\end{array}$ & $\begin{array}{l}1 \text { (Reference) } \\
1.47(1.01,2.15)^{*} \\
1.17(0.81,1.68)\end{array}$ \\
\hline $\begin{array}{l}\text { Parental support } \\
\text { Low } \\
\text { Medium } \\
\text { High }\end{array}$ & $\begin{array}{l}1 \text { (Reference) } \\
1.19(0.81,1.52) \\
0.70(0.51,0.97)^{*}\end{array}$ & $\begin{array}{l}1 \text { (Reference) } \\
0.61(0.39,0.95)^{*} \\
0.37(0.28,0.50)^{* * *}\end{array}$ & $\begin{array}{l}1 \text { (Reference) } \\
0.91(0.68,1.21) \\
0.49(0.33,0.73)^{* * *}\end{array}$ & $\begin{array}{l}1 \text { (Reference) } \\
0.94(0.62,1.43) \\
0.51(0.37,0.70)^{* * *}\end{array}$ \\
\hline Parents not using tobacco & $1.10(0.60,2.02)$ & $0.76(0.55,1.04)$ & $0.91(0.65,1.28)$ & $0.88(0.71,1.09)$ \\
\hline
\end{tabular}

$\mathrm{AOR}=$ Adjusted Odds Ratio; $\mathrm{CI}=$ Confidence Interval; ${ }^{*} * \mathrm{p}<0.001 ; * * \mathrm{P}<0.01 ;{ }^{*} \mathrm{p}<0.05$

\section{Discussion}

This study show the newest results on $\mathrm{OH}$ and $\mathrm{HH}$ in three Caribbean countries. The prevalence of poor $\mathrm{OH}(16.9 \%)$ seemed similar to six countries in Southeast Asia (17.1\%) [3] lower than in 
African countries (22.7\%) [12] and in three countries in Oceania (22\%-38\%) [14]. The prevalence of poor HH (before meals) (68.2\%) was higher than in nine countries in Africa (37.8\%) [12], six Southeast Asian countries (44.8\%) [3], and Pacific island states (30\% to 35\%) [14]. Poor HH (after toilet) (28.4\%) was similar to the Southeast Asian study (31.9\%) [3], but lower than in African countries (41.6\%) [12]. Poor HH (with soap) (52.7\%) was lower than in African countries (65.0\%) [12], but similar to Southeast Asian countries (55.8\%) [3].

Poor $\mathrm{OH}$ was significantly higher in Trinidad and Tobago (22.1\%) than in the Dominican Republic (16.2\%), and poor HH (before meals) was the highest among adolescents in the Dominican Republic. Poor HH (after toilet) was the highest in Dominican Republic (30.7\%), while poor HH (with soap) was the highest in Trinidad and Tobago (60.3\%) in this study. The higher prevalence of poor HH (after toilet) in the Dominican Republic may be attributed to the lowest access to improved water sources and sanitation facilities (86\%), compared to Suriname (93\%) and Trinidad and Tobago (94\%) [15]. The prevalence of poor HH (with soap) was the highest in Trinidad and Tobago $(60.3 \%)$, followed by Suriname (56.2\%) and Dominican Republic (51.2\%), while based on national household surveys, the "percentage of households with a specific place for hand washing where water and soap or other cleansing agent are present" was the highest in Trinidad and Tobago (94.6\%) [16], followed by Suriname (80.1\%) [17] and Dominican Republic (56.1\%) [18]. The national coverage estimates for water and sanitation in schools was $80 \%$ for water $65 \%$ for sanitation in Suriname, and $100 \%$ for water and $100 \%$ for sanitation in Trinidad and Tobago [19]. It is possible that poorer HH among adolescents in Trinidad and Tobago is related to the poor implementation of the Health and Family Life Education (HFLE) school health programme, which includes personal hygiene, in Trinidad and Tobago [20].

While some previous research $[3,10,12,21,22]$ showed a positive association between male sex and poor $\mathrm{OH}$ and/or poor $\mathrm{HH}$, this survey did not find significant sex differences, apart from male sex being negatively associated with poor $\mathrm{HH}$ (after toilet). In a study among adolescents in Zambia, male sex was negatively associated with poor $\mathrm{OH}$ [11]. Compared to students who were never hungry, students who were rarely or sometimes hungry had a higher odds for poor HH (before meals, after toilet and with soap). This result is in line with former studies [11,14,23,24,25], showing an association between lower economic status (experience of hunger) and poor $\mathrm{OH}$ and/or poor $\mathrm{HH}$. It is possible that adolescents from poorer households have less access to tooth brushes and/or soap. 
Consistent with previous studies [3,11,12,14,26-28], this survey showed a positive association between health risk behaviours (current cannabis use, trouble from alcohol use and inadequate fruit and vegetable intake), poor mental health and lack of parental support with poor $\mathrm{OH}$ and/or poor $\mathrm{HH}$ (before meals, and or after toilet, and/or with soap). "It is possible that fruit and vegetable consumption, which is known to have positive effects on well-being, act as mediators in the correlation between poor mental health and personal hygiene" [28]. Contrary to results from previous studies $[3,12,14,21]$, physical inactivity and sedentary behaviour were negatively associated with poor HH (after toilet), and moderate peer support was associated with poor $\mathrm{HH}$ (before meals and with soap). Despite this, other health risk behaviours (current cannabis use, trouble from alcohol use and inadequate fruit and vegetable intake) seem to cluster with poor $\mathrm{OH}$ and/or poor $\mathrm{HH}[3,4,24,29]$. Programmes should promote "hand-washing with soap and tooth brushing with tooth paste", together with the identified clustering health risk behaviours and poor mental health, in order to prevent dental conditions and infectious diseases, such as diarrhea and cholera, in Caribbean countries [2,5-7,30,31].

\section{Conclusions}

This study including three national surveys among school adolescents in the Caribbean in 2016-2017 showed a high proportion of poor $\mathrm{OH}$ (<twice a day tooth brushing) (16.9\%), poor $\mathrm{HH}$ (not always before meals) (68.2\%), poor HH (not always after toilet) $(28.4 \%)$ and poor $\mathrm{HH}$ (not always with soap) (52.7\%). Several sociodemographic factors, health risk behaviours, poor mental health and low parental support were found associated with poor $\mathrm{OH}$ and/or poor $\mathrm{HH}$ behaviour that can assist with tailoring $\mathrm{OH}$ and $\mathrm{HH}$ health promotion. 


\section{Limitations}

The study focused only on school adolescents and was cross-sectional in design. Furthermore, the self-report of the data, including $\mathrm{OH}$ and $\mathrm{HH}$, could have biased responses. Yet, self-reported measures of $\mathrm{OH}$ have been used a proxy tool for reporting indicators of clinical $\mathrm{OH}$ among adolescents [32].

\section{Abbreviations}

GSHS: Global School-Based Student Health Survey; OH: Oral hygiene; HH: Hand hygiene; STATA: Statistics and data

\section{Ethics approval and consent to participate}

The present study was based on an analysis of the 2016 Dominican Republic, 2016 Suriname, and 2017 Trinidad and Tobago GSHS survey datasets freely available online with all identifier information detached. The Dominican Republic 2016 GSHS was approved by "La Organización Panamericana de la Salud" (OPS), the Suriname 2016 GSHS was approved by the Ministry of Health Suriname, and the Trinidad and Tobago 2017 GSHS was approved by the Ministry of Health Trinidad. Therefore, "the permission and ethical approval for the present analysis was automatically deemed unnecessary. Moreover, during the GSHS survey, written assent attached to a questionnaire was obtained from all eligible participants before filling the questionnaire."

Author Contributions: "All authors fulfill the criteria for authorship. S.P. and K.P. conceived and designed the research, performed statistical analysis, drafted the manuscript and made critical revisions of the manuscript for key intellectual content. All authors have read and agreed to the published version of the manuscript."

Funding: "This research received no external funding."

Acknowledgments: "The data source, the World Health Organization NCD Microdata Repository (URL: https://extranet.who.int/ncdsmicrodata/index.php/catalog), is hereby acknowledged.” 
Conflict of Interest: "The authors declare no conflict of interest."

\section{References}

1. Hayasaki H, Saitoh I, Nakakura-Ohshima K. et al. Tooth brushing for oral prophylaxis. Japanese Dental Science Rev. 2014;50(3), 69-77.

2. Curtis V, Cairncross S. Effect of washing hands with soap on diarrhoea risk in the community: a systematic review. Lancet Infect Dis 2003;3(5):275-281.

3. Pengpid S, Peltzer K. Prevalence and associated factors of oral and hand hygiene behaviour among adolescents in six Southeast Asian countries. Int J Adolesc Med Health. 2020;/j/ijamh.ahead-of-print/ijamh-2019-0177/ijamh-2019-0177.xml. doi:10.1515/ijamh2019-0177

4. McKittrick TR, Jacobsen KH. Oral Hygiene and Handwashing Practices among Middle School Students in 15 Latin American and Caribbean Countries. West Indian Med J. 2015;64(3):266268. doi:10.7727/wimj.2014.128

5. Nordhauser J, Rosenfeld J. Adapting a water, sanitation, and hygiene picture-based curriculum in the Dominican Republic. Glob Health Promot. 2019 Nov 17:1757975919848111. doi: 10.1177/1757975919848111.

6. Lund AJ, Keys HM, Leventhal S, Foster JW, Freeman MC. Prevalence of cholera risk factors between migrant Haitians and Dominicans in the Dominican Republic. Rev Panam Salud Publica. 2015; 37(3): 125-132.

7. McLennan JD. Prevention of diarrhoea in a poor District of Santo Domingo, Dominican Republic: Practices, knowledge, and barriers. J Health Popul Nutr. 2000; 18: 15-22.

8. Crombag P, Schuller AA. Prevalence of Caries among Schoolchildren in the Interior of Suriname. Am J Trop Med Hyg. 2018;99(6):1619-1624. doi:10.4269/ajtmh.18-0064

9. Kahar P. Patterns of oral hygiene behaviors, daily habits, and caries prevalence in India and

Dominican Republic: A comparative study. Indian J Dent Res. 2019 Jan-Feb;30(1):87-93. doi: 10.4103/ijdr.IJDR_297_17.

10. McKittrick TR, Jacobsen KH. Oral hygiene practices among middle-school students in 44 lowand middle-income countries. Int Dent J. 2014;64(3):164-70. doi: 10.1111/idj.12094. 
11. Siziya S, Muula AS, Rudatsikira E. Self-reported poor oral hygiene among in-school adolescents in Zambia. BMC Res Notes. 2011 Jul 22;4:255. doi: 10.1186/1756-0500-4-255.

12. Pengpid S, Peltzer K. Hygiene behaviour and associated factors among in-school adolescents in nine African countries. Int J Behav Med 2011;18(2):150-9.

13. World Health Organization (WHO) (2019). Global school-based student health survey (GSHS). URL: https://www.who.int/ncds/surveillance/gshs/en/ (accessed 10 April 2020)

14. Tran D, Phongsavan P, Bauman AE, Havea D, Galea G. Hygiene behaviour of adolescents in the Pacific: Associations with socio-demographic, health behaviour and school environment. Asia Pac J Public Health 2006;18(2): 3-11.

15. Pan American Health Organization. Water and sanitation: Evidence for public policies focused on human rights and public health results. 2011. URL: https://www.paho.org/hq/dmdocuments/2012/Water-Sanitation-final-eng.pdf

16. UNICEF. Trinidad and Tobago. Multiple Indicator Cluster Survey 2011, 2017. URL: https://www.unicef.org/easterncaribbean/media/1221/file/ECA-Trinidad-2011-MICS-Report2017.pdf

17. UNICEF. Suriname: Multiple Indicator Cluster Survey 2018, 2019. URL: https://mics-surveysprod.s3.amazonaws.com/MICS6/Latin\%20America\%20and\%20Caribbean/Suriname/2018/Sur vey\%20findings/Suriname\%202018\%20MICS\%20Survey\%20Findings\%20Report_English.p df

18. UNICEF. Dominican Republic. Multiple Indicator Cluster Survey, 2014. URL: https://micssurveys-

prod.s3.amazonaws.com/MICS5/Latin\%20America\%20and\%20Caribbean/Dominican\%20Re public/2014/Final/Dominican\%20Republic\%202014\%20MICS_Spanish.pdf

19. UNICEF and World Health Organization. Scoping Study: Are data available to monitor the SDGs for WASH in schools and health care facilities in the Latin America and Caribbean region? 2017. URL:

https://www.unicef.org/lac/media/3021/file/PDF\%20Scoping\%20study\%20Portada\%20Scopin g\%20study.\%20Are\%20data\%20available\%20to\%20monitor\%20the\%20SDGs\%20for\%20W ASH\%20in\%20schools\%20and\%20health\%20care\%20facilities\%20in\%20LAC?.pdf

20. Onuoha CA, Dyer-Regis, Onuoha PC. Implementation Levels of a Life-Skill Based School Health Program in a Caribbean country. IJHSR. 2017; 7(4): 353-359. 
21. Peltzer K, Pengpid S. Oral and hand hygiene behaviour and risk factors among in-school adolescents in four Southeast Asian countries. Int J Environ Res Public Health. 2014;11(3):2780-92. doi: 10.3390/ijerph110302780.

22. Sadinejad M, Kelishadi R, Qorbani M, Shahsanai A, Motlagh ME, Ardalan G, Heshmat R, Keikha M. A Nationwide Survey on Some Hygienic Behaviors of Iranian Children and Adolescents: The CASPIAN-IV Study. Int J Prev Med. 2014;5(9):1083-90.

23. Maes L, Vereecken C, Vanobbergen J, Honkala S. Tooth brushing and social characteristics of families in 32 countries. Int Dent J 2006;56(3):159-67.

24. Park YD, Patton LL, Kim HY. Clustering of oral and general health risk behaviors in Korean adolescents: a national representative sample. J Adolesc Health 2010;47(3):277-81.

25. Dobe M, Mandal RN, Jha A. Social determinants of good hand-washing practice (GHP) among adolescents in a rural Indian community. Fam Community Health 2013;36(2):172-7.

26. Zaborski A, Milciuviene S, Bendoraitiene E, Zaborskyte A. Oral health behaviour of adolescents: a comparative study in 35 countries. Stomatologija 2004;6(2):44-50.

27. Slekiene J, Mosler HJ. Does depression moderate handwashing in children? BMC Public Health. 2017;18(1):82. doi: 10.1186/s12889-017-4638-4.

28. Ranasinghe S, Ramesh S, Jacobsen KH. Hygiene and mental health among middle school students in India and 11 other countries. J Infect Public Health. 2016;9(4):42935. doi: 10.1016/j.jiph.2015.11.007.

29. Jordão LMR, Malta DC, Freire MDCM. Simultaneous oral health risk behaviors among adolescents: evidence from the National School-based Student Health Survey. Rev Bras Epidemiol. 2018;21(suppl 1):e180019. doi: 10.1590/1980-549720180019.supl.1.

30. Yvonne A.B. Buunk-Werkhoven, Selma Y. Burrekers. Effects and Benefits of a Program to Promote Tooth Brushing Among 12-Year-Old School Children in the Dominican Republic. Adv Dent \& Oral Health. 2019; 10(5): 555799. DOI: 10.19080/ADOH.2019.10.555799

31. Petersen PE, Bourgeois D, Ogawa H, Estupinan-Day S, Ndiaye C. The global burden of oral diseases and risks to oral health. Bull World Health Organ. 2005;83(9):661-9.

32. Gil GS, Morikava FS, Santin GC, Pintarelli TP, Fraiz FC, Ferreira FM. Reliability of selfreported toothbrushing frequency as an indicator for the assessment of oral hygiene in epidemiological research on caries in adolescents: a cross-sectional study. BMC Med Res Methodol. 2015;15:14. doi: 10.1186/s12874-015-0002-5. 